\title{
GROUP WORK AND COLLABORATIVE LEARNING REVISITED: COACH OR PUMPKIN?
}

Marieken Swart

University of Stellenbosch

As effective teaching and optimal learning are particularly crucial to a developing South Africa, it is perhaps time to take another, closer look at collaborative learning, currently one of the most popular teaching methods. This article examines the theoretical foundation of the method and draws a distinction between it and traditional group work. It assesses the advantages and disadvantages, discusses the kind of learning that takes place during the process of collaboration and whether the method carries particular social benefits. It also explores practical issues such as the role of the tutor, the composition of groups and elements essential to success.

Aangesien effektiewe leermetodes en onderrig van kardinale belang is in 'n ontwikkelende Suid-Afrika, is dit nodig om fyn te besin oor die onderrigmetodes wat gebruik word. Hierdie artikel vergelyk koöperatiewe leermetodes en groepwerk wat tans ooral in gebruik is. Dit bestudeer die teorie wat diè onderigmetodes ondervang, weeg die praktiese vooren nadele, ondersoek die kognitiewe ontwikkeling wat gedurende koöperatiewe groepwerk plaasvind en of die metode enige spesifieke sosiale voordele inhou in multikulturele klaskamers. Praktiese oorwegings soos die rol van die tutor, die strukturering van groepe en die elemente wat suksesvolle toepassing verseker, geniet ook aandag.

\section{INTRODUCTION}

Group activities have been part of teaching activities in some classrooms for many decades. Today the practice is widely used, highly valued and, with the transformation in South African education, it is firmly entrenched as a teaching technique. Yet feelings of disquiet about the buzz word, its twin 'collaborative learning', the difference between the two concepts, the theoretical foundations that support the methods, and the kind of learning that takes place, surface from time to time. This article explores the topic and assesses the educational value of the teaching methods.

\section{A QUESTION OF TERMINOLOGY}

The terms 'group work', 'cooperative learning' and 'collaborative learning' seem to be used indiscriminately throughout the literature on the subject. Terms such as 'peer collaboration', 'coordinated learning' or 'collective learning' also appear frequently and it seems that each of these terms carries its own particular interpretation and approach (Dillenbourg, 1999:20). In practice, group work is frequently equated with cooperative or collaborative learning as if the fact that students are having a group discussion means that they are in fact learning something; that cognitive development is taking place. 
Dillenbourg seems to share my concern about this and points out, in addition, that even learning which seems collaborative might in fact be competitive or coercive if the more powerful members of a group are dictating the terms of the 'collaboration'.

Most researchers such as Johnson and Johnson (1994), Cowie (1994), Rudduck (1990) and Slavin (1995) use the term 'cooperative learning' to refer to group activity with a common goal. Slavin (1995) goes one step further and specifies that 'All cooperative learning methods share the idea that students work together to learn and are responsible for their teammates' learning as well as their own.' (Slavin, 1995:18). The issue of taking responsibility for the learning of others is not, however, common practice in classrooms. The general dictionary definition that collaboration means working together in order to produce something, whilst cooperation also means working together, but seemingly for $a$ common purpose rather than a specific, assessable production, does not do much to distinguish between the two concepts either. Dillenbourg's collection of articles on Collaborative Learning. Cognitive and Computational Approaches provides a useful distinction between cooperative and collaborative learning: cooperation takes place when partners split the work, solve sub-tasks individually and then assemble the partial results in the final output, whereas collaborative learning occurs when partners tackle the entire task together (Dillenbourg, 1999:10).

Dillenbourg also stresses that collaboration has further requirements than merely working together on tasks:

- participants must be engaged in coordinated efforts to solve a problem or perform a task together;

- collaborators must be involved in the construction of a solution that could not otherwise be produced;

- collaborators must reach reciprocal understanding and mutually shared or 'common' knowledge through negotiation of meaning.

[T] here is consensus among researchers that collaboration involves the construction of meaning through interaction with others and can be characterised by a joint commitment to a shared goal.

(Dillenbourg, 1999:21).

The above obviously applies to any collaborative effort like, for example, collaborative group discussions in the business world where learning is not necessarily the objective.

\section{WHAT KIND OF LEARNING TAKES PLACE?}

Obviously collaborative or cooperative learning differs from collaborative group work where the aim is usually restricted to joint commitment to a shared goal or collaborative production. Although both these elements may feature in education, the principle aim is that learning should take place. In education, collaborative learning is characterised by the fact that the sum of knowledge gained by all participants is bigger and better than the parts contributed by any individual, i.e. synergy has occurred. 
Dillenbourg gradually works towards a tentative but careful definition of collaborative learning which points to further distinctions and leads one to a clearer understanding of group situations that do bring about cognitive development.

[T]he words 'collaborative learning' describe a situation in which particular forms of interaction among people are expected to occur, which would trigger learning mechanisms.

(Dillenbourg, 1999:7).

As learning is the ultimate and all-important aim in education, it is clear that the situation, the physical environment, atmosphere and group composition are all crucial contributing factors. Furthermore, students learn in group situations, not because they are placed in groups, but because 'particular forms of interaction' occur. The group members perform certain activities together such as reading, explaining, analysing, evaluating or predicting that in turn trigger learning mechanisms such as induction, deduction, compilation or internalisation. Therefore it is the performed activities that set off specific learning mechanisms, but it must be remembered that 'there is no guarantee that the expected interactions will actually occur' (Dillenbourg, 1999:6). In addition, students also need to reflect on what they are learning; they need to monitor and evaluate the thinking taking place within the group in addition to their own thinking. Once this occurs, collaborative interaction can make a valuable contribution to the learning process. The process can be represented as follows:

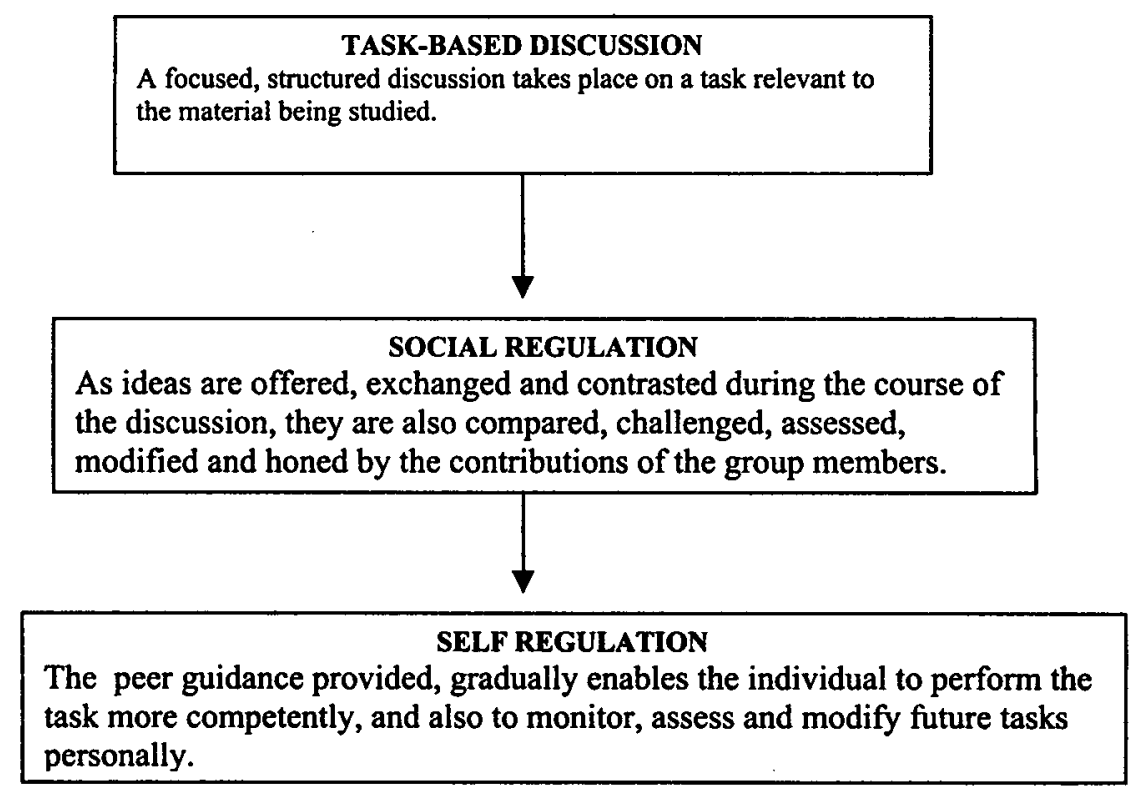

Through the process of social and self regulation, students are able to practice reflective thinking and to internalise knowledge and make it their own. Communication is, according to Lev Vygotsky, an important aspect of the process of internalisation. As 
students grapple with an issue in their groups, thoughts come to the individual mind which at this stage, according to Vygotsky, have not yet been embodied in words. As such, thoughts are called 'inner speech' (Vygotsky, 1986:249). Inner speech is 'condensed, abbreviated speech' which is often fragmented and unstructured (Vygotsky, 1986:182).

It is evident that the transition from inner to external speech is not a simple translation from one language to another. It cannot be achieved by merely vocalising silent speech. It is a complex, dynamic process involving the transformation of the predicative, idiomatic structure of inner speech into syntactically articulated speech intelligible to others.

(Vygotsky, 1986:248).

It is thus imperative to the learning process, particularly in the language classroom, that each student gets ample opportunity to practise making thoughts explicit in a structured, safe, collaborative setting where the student's external speech can be evaluated and shaped by the input of peers. Elsasser (1977:356) provides a neat description of this complex process of transition: 'through this interaction, telegrammatic inner language unfolds to become the basis of competent oral communication.'

Equally important to language learning is that a further transition should take place, namely from external to written speech. Students should be given the opportunity to effect the double transfer from inner to external to written speech as frequently as possible.

The change from maximally compact inner speech to maximally detailed written speech requires what might be called deliberate semantics deliberate structuring of the web of meaning.

(Vygotsky, 1986:182).

Ideally, individuals in the group should also be given the opportunity to collaborate on a final written production so that they can practise reflective and evaluative skills on writing as well. Through this process silent speakers can be empowered to become potent writers, which is after all the educational arena in which the individual's cognitive development will finally be assessed.

\section{QUI DOCET DISCET? DO YOU LEARN TWICE WHEN YOU TEACH?}

The ancient Socratic teaching method has been admired and emulated for centuries. In Socratic teaching, the teacher does not teach by direct exposition of the instructional material as is the case in many classrooms and most lecture halls. Instead the students are guided towards the exploration of meaning and the acquisition of knowledge by exploratory questions. It is thus hardly surprising that theorists consider the practice of explaining to others a source of cognitive development. In collaborative group work the explainer has to formulate thoughts while the receiver accepts or rejects the explanation, asks for further elaboration, for clarification or qualification if there are inconsistencies or information gaps in the explanation. Ploetzner et al (1999:119) discuss the results of their research in this regard and point out that recently conducted research does not support the hypothesis that explaining to others in a collaborative session offers more opportunities for learning than explaining to oneself in individual learning. Instead, 'it has been demonstrated that preparing for teaching, i.e. studying the instructional material 
individually, results in substantial learning'. This point seems to be in line with that postulated by Vygotsky: it is not so much the verbal act of explaining to others that brings about the most learning, but rather the process of reflective thinking and organisation of inner speech or thought that precedes the speech act.

There can be little doubt, however, that the complex process that enables a student to offer an explanation is a learning mechanism that furthers cognitive development. Individual learning provides opportunities for reflection on and organisation of ideas. It does not offer the opportunity for having the reflected product accepted or challenged by peers. This is undoubtedly the main advantage of collaborative learning.

Another advantage is that well-structured collaborative group work should help to wean exam-oriented students from their inclination for surface learning. It should discourage reproductive rote learning whilst encouraging more profound, meaningful learning habits. The ideal is the critical student who does not simply accept a stance or an idea because it is in print; the ideal student challenges, questions, reassesses and truly interacts with learning material.

\section{THEORETICAL ROOTS}

A study of the theoretical origins of collaborative learning throws more light on the kind of learning that takes place and how it occurs. According to Johnson and Johnson (1994:3940), a study of the theoretical sources indicates four main threads, namely the theories of cognitive development, controversy, cognitive restructuring and behavioural learning. In turn, all of these are largely based on the interactionist theories of Piaget and Vygotsky, on the fundamental assumption that interaction among learners around appropriate tasks increases the mastery of critical concepts.

Piaget states that active construction of meaning is fundamental to cognitive development: the learner must be actively involved in the construction of meaningful knowledge. He is deeply opposed to transmission from adult to child as a model for such growth as he believes that the child cannot be critical of adult ideas because of the differences of power and status involved. Ideas must thus be weighed and evaluated on equal terms by peers (Dillenbourg, 1999:22). It thus follows that in collaborative learning situations, groups should consist of peers as far as knowledge, development and proficiency are concerned. Too great an inequity in this regard works against collaborative learning.

Vygotsky's approach provides an altogether more central and constructive role for adults in promoting development. He believes in 'asymmetrical' interactions wherein the level of ability differs markedly. 'Seen from a Vygotskyan perspective, the developmental process is a constructive one, but it is not the child alone who is doing the constructing.' (Dillenbourg, 1999:24). In fact, it is not children alone, or students alone for that matter, who are participating in the construction of meaning, but children/students plus an adult/teacher/tutor who guides or steers the interaction. In groups left unguided for too long, the discussion frequently becomes circular or bogged down in the mud of trivialities. Judicious guidance is thus essential. 
Vygotsky's theories on the Zone of Proximal Development (ZPD) are crucial to an understanding of his approach to cognitive development. Vygotsky (1978:86) defines this zone as:

\section{the distance between the actual developmental level as determined by independent problem solving and the level of potential development as determined under adult guidance or in collaboration with more capable peers.}

According to this concept, each individual has a central core of internalised knowledge which is surrounded by his or her ZPD area, an area in which the individual has some knowledge but 'not the full structure of capacities required' to perform a task (Ploetzner $e t$ $a l, 1999: 185)$. In well-balanced groups, each person's core knowledge and ZPD overlap with those of the other group members. Thus 'each person can support cognitive development in the group by providing 'scaffolding' for others', but this collective potential can only be realised if each member of the group is aware of the knowledge of others, and can offer help and receive help from others (Ploetzner et al, 1999:185). The proviso that each member must be aware of the knowledge of others is crucial as it demands that all students must have an opportunity to contribute and interact during the group discussion. Dominance of discussions due to inequity within the group is obviously not what Vygotsky means by adult guidance.

As language is the means by which learners systematise their perceptions, as words are used to formulate generalisations, abstractions, conclusions, qualifications and other forms of mediated thinking, the level of language used by the group members is extremely important to both cognitive and social development. This raises the question whether a language course can use collaborative group work to teach mixed groups of first and second language learners. For communication to be successful there must be accord between reciprocally communicating members: the verbal expression of one participant must be perceptible to and within a meaningful frame of reference for the other participants. This entails more than explaining big words as 'these words, the fragile bridges upon which our thoughts must travel, are sociohistorically determined and therefore shaped, limited, or expanded through collective and individual experience.' (Elsasser, 1977:5). Linguistically more advanced first language students normally do not have the ability or skill to act as facilitators or guides to second language students and consequently tend to dominate because of their greater language proficiency rather than their intellectual ability or insight. This can be severely detrimental to reflective collaborative learning and also against Vygotsky's principle that it should be 'collaboration with more capable peers' not with students from a higher level of language development (Vygotsky, 1978:86). A further important point here is that, as knowledge is generated through mental and physical activities, the learner does not learn through assimilating someone else's knowledge, but must be involved actively in producing own knowledge (Schwartz, 1999:216). Thus the passive second language student who merely listens to first language group members without participating or being allowed to participate, will probably not develop cognitively and might just as well be sitting passively in a lecture.

Individual cognitive development is, therefore, seen as a process of internalising socially regulated and mediated knowledge. The learner's understanding of the world is mediated by and built up through interaction with others, and meanings are negotiated, established and internalised through what is known as a 'social constructivist' approach (Dillenbourg, 1999:24). 
Related to the developmental theorists are the controversy theorists who posit that being confronted with opposing points of view creates uncertainty or conceptual conflict, which in turn creates a process of reconception and a resultant information search. All these processes finally lead to wider and deeper perspectives on issues, productive questioning and challenging and more refined and thoughtful conclusions. In South Africa where it is crucial for students from different ethnic backgrounds to tolerate, appreciate and understand different perspectives, collaborative group work can be of great value. In fact, one might say that students not exposed to such interactions are disadvantaged.

The third group, the cognitive reconstructuring theorists state that in order for information to be retained in the memory and incorporated into existing cognitive structures, the learner must cognitively rehearse and restructure the material (Johnson and Johnson, 1994:39-40). Effective ways of doing this are in-depth group discussions, various activities with the same material, and explanations to a collaborator. This approach is in turn strongly supported by neurological research regarding the optimal functioning of the brain. In his article 'The brain and accelerative learning', James Hand (1986:6) states that 'When a learned item is practised many times in many different ways' greater cognitive assimilation takes place as 'the neurons make new connections with different cells, branching the message to several sites of the brain and networking the information'.

The behavioural learning theorists (such as Skinner's stimulus response theory and operant conditioning) focus on the impact of group reinforcers and rewards for learning and it is Slavin in particular who has emphasised the need for extrinsic rewards in group work. Three concepts are crucial to Slavin's understanding of cooperative learning, namely 'team rewards, individual accountability and equal opportunities for success' (Slavin, 1995:5). Other researchers do not refer specifically to the importance of team rewards wherein teams may earn certificates or other team rewards. Slavin posits that cooperation between students is encouraged by these classroom rewards and by the teacher or tutor who tries to communicate an all-for-one-and-one-for-all attitude. Furthermore, sessions are carefully structured so that each student has a chance to make a substantial contribution to the team effort (Slavin, 1995:18). This approach works particularly well in junior school where teaching is not constrained by different periods for different subjects and the groups can work uninterruptedly together on a task for an extended period. It also functions effectively at post-graduate level with more mature students in, for example, courses in business administration (MBA), particularly when the group members are from different sections in a corporation and need the expertise of all their members to complete the task. The greatest challenge to the educator here is to design an effective and fair form of evaluation. Generally speaking, group evaluation is a tricky business that can be problematic if care is not taken against practices of 'free-riding'. It does, however, provide incentive for students to make the group process work if, for the team to succeed, individual marks are dependent on all group members mastering the skills or the knowledge.

Cowie and Rudduck $(1991: 5,7)$ stress that the whole point of group work is providing students with the opportunity to learn through the expression and exploration of diverse ideas and experiences. It is not about scoring off others, not about competing or winning, but 'about using the diverse resources available in a group to deepen understanding, sharpen judgement and extend knowledge'. They maintain that students gain depth of 
understanding and learning in applying different concepts, testing hypotheses, interpreting and analysing data and relating learning to their own experiences.

\section{SOCIAL BENEFITS}

In line with the controversy theorists, the effects of collaborative group work on relationships in multicultural groups have been widely researched and documented in the U.S.A. and this is obviously extremely important to education in South Africa. The Green Paper on Higher Education Transformation provides specific guidelines. It supports:

- a democratic ethos and a culture of human rights by educational programmes and practices conducive to critical discourse and experimental thinking, cultural tolerance, and a common commitment to humane, non-racist and non-sexist social order (1996:5).

- an academic climate characterised by free and open debate, critical questioning of prevailing orthodoxies, and experimentation with new ideas (1996:8).

Most educationists would agree that well-structured collaborative group work provides the ideal solution to the problem of providing students from different ethnic groups with opportunity for non-superficial, cooperative interaction. It does have the potential to challenge prejudices, to promote cultural tolerance, experimentation with new ideas and nonracist and nonsexist social attitudes. But, once again, these aims are not automatically realized in group sessions.

It is interesting to note how frequently comments by researchers about group activities are carefully qualified. Such an example comes from one of the strongest supporters of the method. Slavin says that:

research has established that under certain circumstances the use of cooperative learning methods increases student achievement more than traditional practices. In addition, these methods considerably improve students' self-esteem and social relations among students, in particular, race relations and acceptance of mainstreamed students.

(Cowie and Smith, 1994:60)(my italics).

Cowie et al (1994) document the research of Aronson who found a positive effect on tolerance, acceptance and trust among children from different ethnic backgrounds. Johnson and Johnson (1994) report equally positively on outcomes in the promotion of learning and in increased altruism, and Kagan suggests:

[T] he results of cooperative learning studies indicate that with relatively little time and expense, by reorganising the social structure of the classroom, radical improvements in race relations can be obtained consistently.

(Kagan, 1990:13)(my emphasis). 
At the end of their book, however, Cowie et al admit that their main research aim to see whether cooperative group work (CGW) would have a positive impact on difficulties in children's social relationships in school, is one of failure. Their results in their project 'Prejudice, isolation and bullying: intervention in ethnically mixed classrooms' (1991:196), show that:

- there was no impact on measures of friendship and sociometric status;

- overall liking scores did not increase more in the CGW classes, nor was there any greater change or decrease in numbers of children who were sociometrically neglected or rejected;

- there was no impact on bully scores;

- there was no impact on measures of racial or ethnic prejudice.

They conclude that 'On the basis of our project, we feel that CGW is not a panacea for coping with social relationship difficulties in classrooms' (1999:199).

Although they reiterate their belief in the potential of CGW based on U.S. and Israeli studies, they believe their study to have been ecologically valid in the sense of what is achievable in more difficult but realistic inner city conditions. The other studies, they believe, had been set up in ideal experimental conditions and selected classroom situations that reflect, in general, short-term effects. In her meticulous observations of real-life classrooms, Hertz-Lazarowitz concurs and also concludes that 'even when tasks are structured to facilitate cooperation, interactive behaviours do not necessarily occur, and neither do helping behaviours' (Hertz-Lazarowitz and Miller, 1992:60).

The objective here is not to suggest that collaborative group work has no social benefit in a multicultural environment, but rather that educationists should be aware of the fact that successful multicultural interaction is not automatically achieved and that group work is not a panacea' for better racial relationships. In particular, Cowie et al (1991:201) point out that to achieve greater racial harmony and understanding, teachers will need quite specific training in mediation, counselling and conflict resolution skills and that they also need sufficient time to work with individuals and small groups. The pressure of traditional secondary and tertiary timetables does not always provide the ideal opportunity for this.

\section{THE ROLE OF THE TUTOR: THE GUIDE ON THE SIDE}

In collaborative group work the tutor assumes the role of a facilitator who guides the learner towards collaboration and cognitive development. The role does not demand strong authority as in the traditional classroom, but a firm guiding hand and the ability to foster the social skills referred to above. An honours student who wrote an article in response to research on this topic and her own experiences as a facilitating tutor in our English department, comments as follows:

At times my students were resistant to working in groups, particularly if the subject to be covered was somewhat mundane, and at these times the discipline and productivity of my classroom suffered greatly. A kind of competition, group score, or additional incentive was definitely necessary at this stage to revive interest and enthusiasm. More thought and energy was therefore necessary in the design of lessons. There is no 
doubt that collaborative learning requires a great deal more from teachers in terms of learning the subtleties of discipline and facilitation under these conditions, and of learning to incorporate group work into the design and content of their material. A great deal more thought and preparation is required for lessons to be successful.

Just how much planning should go into the sessions is clear when one realises that the sessions to which this student is referring had indeed been carefully planned by two or three tutors working on the design together. Bejarano (1987:483-499) comments that:

Implementation of this approach [CGW] requires intensive teacher training for the use of techniques, both in terms of operational procedures in the classroom and in terms of appropriate design of the learning tasks.

A number of researchers, among them Slavin and Kagan, provide useful guidelines regarding the different interactive structures or operational procedures that can and should be used and the specific situations and tasks for which they are most suitable (Slavin 1995, Kagan, 1990). Kagan (1990:15) maintains that:

Because each collaborative learning structure has distinct domains of usefulness and can more effectively reach some but not other cognitive, academic, and social goals, the efficient design of lessons involves using a variety of structures, each chosen for the goals it best accomplishes. Reliance on any one structure limits the cognitive and social learning of students.

Vygotsky's theories on collaborative learning indicate quite clearly that the tutor, in the role of successful facilitator, also has to have clarity on the proficiency of each student; he/she has to understand the parameters of the zones of proximal development of the students so that the tasks, interaction and the constitution of groups complement the ZPD of the individual. The students must be given appropriate support and guidance to enable them to move through this zone. Hamilton and Ghatula (1994:337) comment as follows:

If tasks are below or above the student's zone of proximal development, low levels may result. That is, a task that is below the zone will not be challenging and may lead to boredom, while a task above the zone may be frustrating and lead to avoidance.

Contrary to general belief, and probably practice, Johnson and Johnson (1994:114) maintain that the facilitator's job begins in earnest when the collaborative groups start working. Facilitators should observe carefully the interaction among group members to assess academic progress and appropriate use of interpersonal and small-group skills. They suggest that observations can be formal through use of an observation schedule that is filled in by the facilitator, or anecdotal through informal descriptions of students' statements and actions. Alternatively, each group member can be given a checklist for assessment of individual contributions and group synergy. The facilitator's task is therefore to assess as accurately as possible how successful the collaborative interactions and learning have been in each group and in the class as a whole. They should intervene, when necessary, to aid understanding, to re-establish direction and focus and to suggest more effective social interaction. A final plenary session, when the class can reflect on 
their understanding of the material dealt with and the success of their particular group interaction, is essential. Time constraints might make this impossible in every session, but regular feedback is undoubtedly important.

Facilitators should also ensure at all times that the overall objective of the session and the aims of each activity have been well defined and made explicit to the participants to ensure active learning and cognitive development. Furthermore, they should try to maintain the delicate balance between discipline and freedom. Their students should be encouraged to develop their own strategies and meaning, but this should be done with rigour and discipline.

\section{ELEMENTS ESSENTIAL TO COLLABORATIVE LEARNING}

Facilitators should also be able to evaluate the type of talking that occurs during the interactions. Mercer and colleagues identify three types of group talk of which only one is really productive, namely Exploratory Talk which 'demonstrates the active joint engagement of the participants with one another's ideas' (Dillenbourg, 1999:25). During such talk, challenges and counter-challenges occur and justifications and alternatives are offered. These are all hallmarks of critical thinking. Disputational Talk or unproductive disagreement which does not lead to compromise or resolution should be pointed out and redirected. So should Cumulative Talk which simply adds uncritically to what has gone before through superficial amendments. Participants should be made aware of these distinctions, and should ultimately be able to monitor their own group interactions. One can clearly see just how beneficial such analytical skills would be to the learning process in general, and eventually to the student entering the professional world.

It would seem that researchers agree that certain elements are essential to successful collaborative learning. Johnson and Johnson identify five such elements. Firstly, learners must develop 'Positive Interdependence'; they must have vested interests in each others' achievements: they must believe in sharing resources, helping and assisting each other and providing mutual support and celebrating joint successes (Johnson and Johnson, 1994:22). Given the competitive world that has spawned learners, to achieve what Johnson calls 'Positive Interdependence' is no easy task. Secondly, students must be encouraged to promote each other's success and cognitive development; they must strive for 'Promotive Interaction'. Thirdly, there must be 'Individual Accountability', which ensures that each participant knows who in the group needs more assistance, support and encouragement and that no one can 'hitchhike' on the work of others. The fourth point is based on the acknowledgement that collaborative learning is inherently more complex than competitive and individualistic learning. Consequently, 'Interpersonal and Small-group Skills' must be taught so that students are motivated to engage in high-quality interaction. 'Leadership, decision-making, trust-building, communication and conflict-management skills have to be taught just as purposefully and precisely as academic skills' (Johnson and Johnson, 1994:23). The fifth essential component of collaborative learning is 'Group Processing'. Group members should discuss how well they are achieving their goal and maintaining effective working relationships. They need to identify helpful and unhelpful group actions so that their interactions move onto a conscious plane. Above all a change in mind-set is essential: learning must be seen as something a learner does, not as something that is done to him (Johnson and Johnson, 1994:23). 
Researchers are thus clear on the distinction between traditional group work and cooperative/collaborative group work as shown in the following table comparing the characteristics of the two activities.

Traditional Group Work

\begin{tabular}{|c|c|}
\hline Low interdependence & High positive interdependence \\
\hline Only responsible for self & Joint responsibility \\
\hline Focus on individual performance & Focus on joint performance \\
\hline Individual accountability only & Group and individual accountability \\
\hline Competition rather than cooperation & $\begin{array}{l}\text { Promoting, helping and supporting each } \\
\text { other's efforts to learn }\end{array}$ \\
\hline Little structure provided & $\begin{array}{l}\text { Structures in place to facilitate interaction } \\
\text { and interdependence }\end{array}$ \\
\hline Na specific training & $\begin{array}{l}\text { Training in teamwork and social } \\
\text { interaction provided }\end{array}$ \\
\hline No group evaluation of interactivity & $\begin{array}{l}\text { Groups assess quality of work and } \\
\text { individual input }\end{array}$ \\
\hline $\begin{array}{l}\text { Reward for individual accomplish- } \\
\text { ment }\end{array}$ & $\begin{array}{l}\text { Formal assessment of work done by group } \\
\text { and individual contributions }\end{array}$ \\
\hline
\end{tabular}

(Adapted from: Johnson and Johnson 1994:78)

The above description of traditional group work would characterise most group activities in education today and it is clear that these are not situations in which group learning will necessarily occur. The strong position occupied by performance, responsibility, accountability, and assessed accomplishment of the individual does not promote collaborative learning and collective cognitive development. The individual may still be unwilling to share knowledge or insight with less able peers if there is no personal gain. Although group work might be an enjoyable classroom activity that generates much talk and social interaction, there is no guarantee that any significant learning is taking place.

In future, hopefully, teacher trainees will learn how to accomplish these goals and transfer the necessary skills. Currently it seems that the majority of lecturers and teachers have heard of these trends, have attended a workshop or two and have read a few articles, but on the whole we are essentially still engaging in hit-and-miss methodology when it comes to collaborative learning. 


\section{THE COMPOSITION OF GROUPS}

Just how groups should be formed is another important issue. The general rule of thumb is the smaller the better, especially if time is limited. Group sizes may vary according to specific objectives and circumstances. Bigger groups mean a greater range of abilities, 'core' and ZPD of knowledge, but, on the other hand, require greater social and communicative skills for successful interaction and more time for equal participation.

A question that is frequently asked is how learners should be assigned to groups. Random assignment of students, counting them off in groups from one to four (six or seven, depending on the numbers in the class) with all the ones, for example, forming one group, is probably the easiest method. One could use stratified random assignment in which groups consist of high, medium and low scorers in a pre-test, or assign them according to learning styles. The tutor can also allocate a minority of non-achievement oriented students to a group, or deliberately isolate disruptive students. A successful method of allocation according to Johnson and Johnson is to ask students to list 3 classmates with whom they would like to work. Students are then placed in a group with one of their listed favourites. In this way a list of 'isolates' or less popular students can be drawn up that will enable the tutor to place them in groups with more skilful and supportive students (Johnson and Johnson, 1994:104). The least recommended method is for learners to choose their own groups as these are often homogeneous in ability, interests or points of view. Groups should generally be allowed to remain stable long enough for them to function successfully. If one breaks up unsuccessful groups too soon, the members do not learn to adapt and cope with conflict situations.

A more complex issue is whether groups should be homogeneous or heterogeneous in composition. Dillenbourg supports the principle of heterogeneous viewpoints, approaches and strategies, thus both the controversy and cognitive reconstructuring theories. This promotes more 'elaborative thinking', more frequent giving and receiving of explanations, and more challenging and reflective thinking. All of these learning mechanisms increase depth of understanding, the quality of reasoning, and finally long-term retention rather than rote learning. However, Dillenbourg (1999:9) also stresses the importance of symmetry of action, knowledge and status. He says that he feels 'intuitively' that:

a situation is termed 'collaborative' if peers are (i) more or less at the same level and can perform the same actions, (ii) have a common goal, and (iii) work together (1999:9).

Practical experience with group work over many years prompts support for this definition, particularly the importance of symmetry in collaborative efforts. It is vital to successful interaction that the same actions are allowed to each participant in the group so that no one is marginalised by constantly being assigned 'lesser' duties because of perceived inequality. To achieve this, symmetry of knowledge, skills or development, and status is essential. This does not mean that on a given task one member might not have greater knowledge than the others. However, the moment one group member is always given greater status because, for example, he/she is a mother tongue speaker amongst second or third language speakers in a language class, the symmetry of the group collaboration is skewed and the other group members, who are not able to participate on an equal footing, are inhibited or disempowered. This kind of symmetry should not be confused with the advantages gained from the clash of heterogeneous viewpoints, strategic competence and even problem- 
solving strategies as these exercise a positive influence by stimulating discussion and broadening perspectives.

Collaborative group work is particularly beneficial in the second and foreign language classroom. The mutual dependence that collaboratively structured activities require leads to more communication as the students need to exchange information in order to complete the task successfully. Spontaneous communication can take place because students are working without pressure from their peers. Learners are less inhibited and less afraid of making mistakes in these small groups. As their confidence increases, so do their language ability and their willingness to take risks. They are interacting in a safe, protected environment. The same is, of course, true of first language classrooms. Here learners are able to focus on more effective, subtle formulation of thoughts and perhaps to interact on a more sophisticated, abstract level.

The ideal composition of groups raises the question of the gifted student. Jacobs (1988:98) claims that:

contrary to what many people expect, research has shown that the learning of high-achieving students usually benefited and never suffered when they were grouped with lower-achieving peers.

High-achievers would certainly benefit from discussion, would learn through explaining to others, and would certainly not suffer, but if they are consistently grouped with lowerachieving students they would not benefit as much as they would if they were challenged during collaborative interactions by their equals or their superiors. Vygotsky certainly speaks of 'collaboration with more capable peers' and says that:

Instruction is useful when it moves ahead of development. Instruction would be completely unnecessary if it merely utilised what had already matured in the developmental process, if it were not a source of development (1987:212).

But we must consider the upper threshold as well; instruction must be oriented towards the future, not the past (1987:189).

It is thus unfair not to expose the high-achiever to situations that 'move ahead of development'. When high-achievers are consistently isolated in groups with lower achievers one finds that the latter tend to rely on the gifted students who, on the other hand, come to resent the fact that they have 'to do all the work'. When other group members are free-riding, hard workers often reduce their efforts or withdraw to avoid being seen as 'suckers'. If asymmetrical proficiency is unavoidable in groups, the facilitator should make use of strategies to correct the imbalance. Such strategies would include assigning alternating specific roles to the group members to ensure that neither free-riding, withdrawal nor dominance occur.

A further issue is that some students genuinely dislike group work. They prefer to work on a problem at their own pace (whether fast or slow) and in their own time. Such students should be encouraged to participate effectively in group efforts if their preference is based on lack of social skills. However, room should also be allowed for the students who genuinely prefer personal engagement with a challenging task. If group work is used to excess or indiscriminately in classes, students tend to build up an open resistance to it that 
has a detrimental effect on class attitude and atmosphere and, consequently, on effective learning.

\section{A FEW FINAL THOUGHTS}

Lecturing, the most common form of teaching in secondary and tertiary institutions, is fast losing favour as it involves an extended teacher-centered presentation of material which typically results in the learner being relegated to the role of passive spectator.

Our survey of teaching methods suggests that ... if we want students to become effective in meaningful learning and thinking, they need to spend more time in active, meaningful learning and thinking - not just sitting and passively receiving information.

(McKeachie, in Johnson and Johnson: 1994:123)

Collaborative group work, on the other hand, encourages (ideally) active, organic learning. The only problem of course is that it demands small group tutoring which is expensive, particularly at a time when the teacher/student ratio is being reduced virtually across the board for financial reasons. What then should the solution be for courses catering for large groups of students? Perhaps a partial solution lies in a combination of the two methods that could be represented graphically in the following way for the worst-scenario teaching situation: the forty-minute lecture.

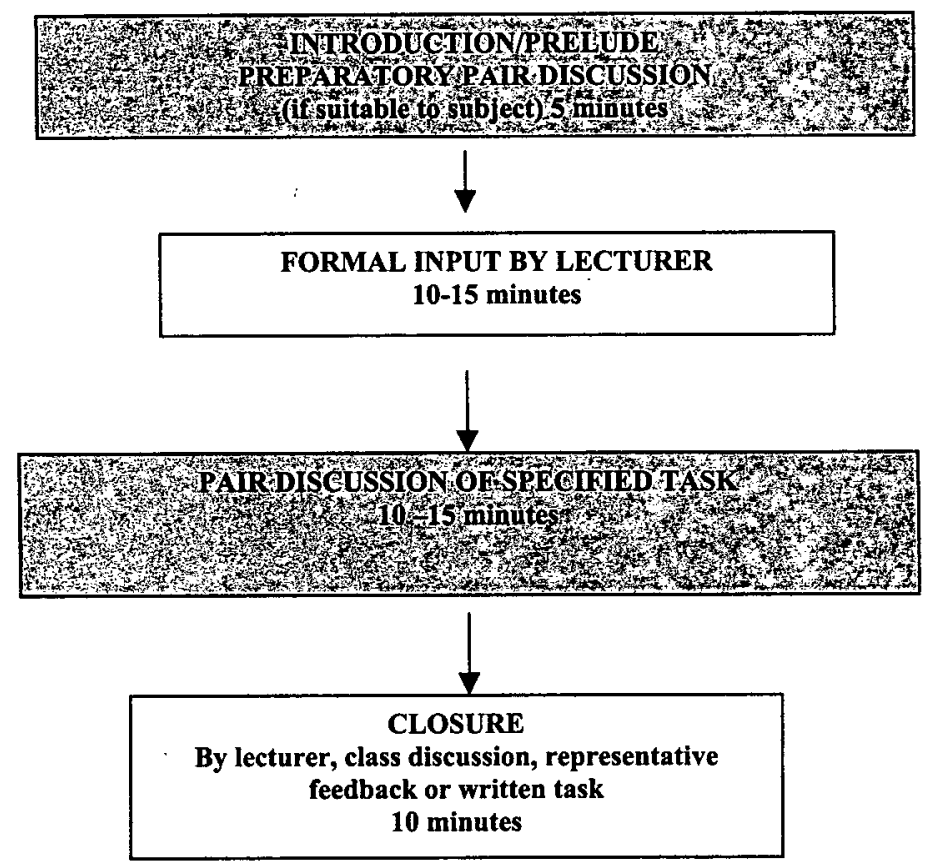

The allocation of time and the sequencing of activities can be adjusted to suit different circumstances. An Introduction or Prelude to the main activity would only be used with 
subject matter about which the students have preconceived ideas. If it concerns an issue about which they have certain prejudices, such an introduction paves the way for a spirited discussion. During the pair discussion that follows the lecturer's input, students could be asked to formulate individual responses to a question first before being asked to discuss their responses with partners. They could then be asked to formulate an improved version together based on both contributions. Closure could entail feedback from randomly selected pairs (as students have already formulated a response they are more willing to respond, even in large groups). This also enables the lecturer to assess how well the students have coped with the material presented. This kind of Closure is often a sobering experience as lecturers tend to expect students to understand a concept merely because it has been explained to them, whereas students need time for cognitive processing. They will obviously also benefit from the pair discussion on an issue that will be picked up again in the Closure.

A balanced, varied, eclectic approach to teaching is essential. Band-wagon tendencies towards particular methods or euphoric and uncritical acceptance of methodological trends have proven to be costly in the past. Maintaining that collaborative group work is more beneficial to students and should be used above other methods in all circumstances is clearly impractical and unwise. Collaborative group work is rightly supported by most educationists because of its intrinsic values of sharing, supporting and communicating. It can maximise outcomes such as multicultural awareness and tolerance, reflective, critical thinking, cooperation, compromise and confidence. Finally, it can be the vehicle that will enable students to manage the meaningful transfer of knowledge gained to real-life cooperative relationships in the professional world where teamwork is important. Without judicious, expert use, however, it is an illusion; it turns into a pumpkin incapable of transporting anyone towards a cognitive goal. Collaborative group work can be an effective teaching method, but it is not the easy way out.

\section{REFERENCES}

BEJARANO, Y. 1987. A cooperative small-group methodology in the language classroom. Tesol Quarterly, 21(3):483-499.

COWIE, H AND J RUDDUCK. 1990. Cooperative learning. Traditions and transitions. London: BP Educational Service.

COWIE, H, P SMITH, M BOULTON AND R LAVER. 1994. Cooperation in the multiethnic classroom. London: David Fulton Publishers.

DILLENBOURG, P. (ed). 1999. Collaborative learning. Cognitive and computational approaches. Oxford: Pergamon.

ELSASSER, N, AND VP JOHN-STEINER. 1977. An interactionist approach to advancing literacy. Harvard Educational Review, 47(3):355-369.

Green paper on higher education transformation. Department of Education, Pretoria, December 1996. 5-8. 
HAMILTON, R, AND E GHATULA. 1994. Learning and instruction. New York: Mcgraw-Hill.

HAND, JD. 1986. The brain and accelerative learning. Per Linguam, 2(2):2-13.

HERTZ-LAZAROWITZ, R AND N MILLER. 1992. Interaction in cooperative groups: theoretical anatomy of group learning. Cambridge: Cambridge University Press.

JACOBS, G. 1988. Cooperative goal structure: a way to improve your group activities. ELT, 42(2):97-101.

JOHNSON, DW AND RT JOHNSON. 1994. Learning together and alone. $4^{\text {th }}$ ed. Needham Heights, Massachusetts: Allyn and Bacon.

KAGAN, S. 1990. The structural approach to cooperative learning. Educational Leadership, 47 (4):12-15.

PLOETZNER, R, P DILLENBOURG, M PREIER AND D TRAUM. 1999. Learning by explaining to oneself and others. In P Dillenbourg (ed.), Collaborative learning. Cognitive and computational apprqaches. Oxford: Pergamon. 103-121.

SLAVIN, RE. 1995. Cooperative learning: theory, research and practice. Englewood Cliffs: Prentice-Hall.

SCHWARTZ, DL. 1999. The productive agency that drives collaborative learning. Collaborative learning. Cognitive and computational approaches. Oxford: Pergamon 197-219.

VYGOTSKY, L. 1986. Thought and language. Massachusetts: Massachusetts Institution of Technology. 